\title{
Concepções dos tutores do programa Unesp/ Univesp sobre formação a distância
}

\author{
Marta Fernandes Garcia \\ Dirceu da Silva \\ Universidade de Campinas
}

\section{Resumo}

0 texto apresenta o perfil dos tutores do programa Unesp/Univesp e discute as concepções que esses sujeitos possuem sobre aspectos da formação a distância. Para tanto, foi aplicado um questionário em 41 tutores. Os resultados mostram que, de maneira geral, os tutores acreditam na EaD para uma formação de qualidade de professores e consideram o trabalho de tutoria fundamental para garantir a qualidade da interação entre os alunos. Os materiais instrucionais ocupam um lugar de destaque no processo de aprendizagem para um número considerável de sujeitos. Suas concepções também evidenciam que o preconceito com a EaD ainda é forte no mercado de trabalho.

Palavras-chave: Concepções. Perfil do Tutor. Formação de Professores. Educação a Distância. 


\section{Conceptions of the tutors in the Unesp/Univesp program about distance education}

This text presents the profiles of the tutors in the Unesp/Univesp program and discusses their conceptions of different aspects of distance education. This was accomplished by presenting a questionnaire to 41 tutors. The results show that, in general, the tutors believe that distance education is capable of offering quality teacher training, and consider the tutoring work indispensable to guarantee the quality of the interactions among students. A considerable number of tutors considered the educational materials highly valuable for the learning process. Their conceptions also showed that there is still strong prejudice against distance learning in the labor market.

Keywords: Conceptions. Tutor Profile. Teacher Training. Distance Learning.

\section{Concepciones de los tutores del programa Unesp/Univesp sobre formación a distancia}

El texto presenta el perfil de los tutores del programa Unesp/Univesp y discute las concepciones que esos sujetos tienen sobre aspectos de la formación a distancia. Para tanto, un cuestionario fue realizado a 41 tutores. Los resultados muestran que, en general, los tutores creen en EaD para la formación de calidad de los profesores y piensan el trabajo de tutoría cómo fundamental para garantizar la calidad de la interacción entre los estudiantes. Los materiales de instrucción ocupan un lugar destacado en el proceso de aprendizaje para um número considerable de sujetos. Sus concepciones también muestran que el prejuicio con EaD sigue siendo fuerte en el mercado de trabajo.

Palabras-clave: Concepciones. Perfil del Tutor. Formación de Profesores. Educación a Distancia. 


\section{Introdução}

As inovações e as rápidas transformações tecnológicas a que assistimos permitiram que a educação a distância evoluísse ao longo dos anos. Já passamos por três gerações: correspondência, telecomunicação e telemática e, hoje, presenciamos a quarta, via internet (García Aretio, 2003). Esta última, particularmente, possibilita a realização e oferecimento do ensino com a utilização de recursos de comunicação e interação, o que contribui significativamente para a superação das distâncias geográficas e para a ampliação da oferta neste nível de ensino. Em um país como o Brasil em que menos de $20 \%$ dos jovens com idade entre 18 e 24 anos têm acesso ao ensino superior e onde a rede privada atende quase $80 \%$ dos estudantes (IBGE, 2009), a educação a distância pode contribuir largamente para o acesso a processos formativos neste nível e para a redução da exclusão e injustiça social. No entanto, para além da quantidade, é necessário garantir a qualidade desse processo, que inicia com o entendimento de educação como bem público. (Dias Sobrinho, 2010)

Com o avanço da tecnologia e a inauguração dos ambientes virtuais de aprendizagem (AVAs), novas propostas educacionais têm surgido. Na esfera pública, a educação a distância também tem sido estrategicamente utilizada para atender a demanda que necessita de formação inicial e continuada. Desde a década de 50, várias experiências foram realizadas a distância no Brasil, tanto no setor público como no privado, mas somente em 1995 iniciou-se o primeiro curso de graduação a distância, a licenciatura em Educação, resultado da parceria entre a Universidade Federal de Mato Grosso (UFMT) e a Secretaria de Estado de Educação do Mato Grosso (Preti, 2005). Assim, é importante perceber que a trajetória da educação superior a distância via internet não possui longa história em nosso país, apesar do grande e rápido crescimento a que temos presenciado. (Giolo, 2008)

Ao lado desse significativo crescimento da EaD, surgem novos e diferentes campos profissionais que aparecem para dar conta daquilo que Mill (2010) denomina de polidocência, ou seja, uma docência coletiva e fragmentada em que cada parte do trabalho docente é realizada por um distinto profissional. Assim, segundo o autor e também consoante com as proposições de Belloni (2003), na EaD o processo de ensino-aprendizagem é muito mais complexo, e quem ensina nessa modalidade é um conjunto de profissionais. Neste cenário, surge um profissional ainda não compreendido completamente, o tutor. Na grande maioria das vezes, trata-se de sujeitos que frequentaram cursos presenciais e que possuem pouca ou nenhuma experiência em EaD. Desta forma, esses profissionais, genericamente chamados de tutores ${ }^{1}$, encontram diante de si um novo cenário, que traz consigo novos desafios e que exige outra forma de ensinar e aprender. Assim, uma nova cultura é estabelecida para a qual professores e alunos não foram preparados para enfrentar. (Kenski,

1. Utilizamos o termo genericamente, pois o profissional tutor recebe diferentes nomenclaturas dependendo da instituição ou do programa educacional onde atua. 
1998; Palloff; Pratt, 2004; Moore; Kearsley, 2008; Belloni, 2009; Lapa; Pretto, 2010; Schlemmer, 2010)

Ainda que seja coletivo e desenvolvido por diferentes profissionais, o trabalho do tutor é fundamental na educação a distância. No programa da Universidade Estadual Paulista Júlio de Mesquita Filho no âmbito da Universidade Virtual do Estado de São Paulo (Unesp/Univesp), em andamento no Estado de São Paulo, ele recebe o nome de orientador de disciplina e é responsável por cuidar da formação dos professores em exercício nos momentos presenciais e virtuais. Por se tratar de um contexto de formação de professores experientes no magistério, como é o caso do programa em estudo, é importante ressaltar que o trabalho do tutor se torna ainda mais desafiador, pois ele tem de lidar com alunos com experiência profissional, com atitudes e hábitos consolidados e esquemas de ação desenvolvidos que thes dão certa segurança e confiança no próprio trabalho (Alonso; Alegretti, 2003). Assim, a atuação dos tutores nesse programa exige sólidos conhecimentos da área de formação em que desenvolvem sua prática bem como sobre educação a distância.

Neste sentido, diante da complexidade que envolve a prática do tutor e da relevância da sua atuação, interessa-nos neste artigo refletir sobre as concepções que os tutores do programa Unesp/Univesp possuem sobre aspectos da formação a distância, entendendo que as concepções são suportes para a ação (Garnica, 2008) e, portanto, podem desencadear boas práticas, centradas na aprendizagem dos alunos e na crença de que é possível aprender e ensinar em ambientes virtuais ou mesmo enveredar para práticas tradicionais, com caráter mais administrativo do que pedagógico.

\section{0 programa de formação de professores da Unesp/Univesp}

\section{Contexto geral}

0 programa Unesp/Univesp refere-se ao curso de licenciatura em pedagogia, na modalidade a distância, para a formação de professores em exercício para a educação infantil, para os anos iniciais do ensino fundamental e para a gestão da unidade escolar, entre os anos de 2010 e 2013. 0 programa está sendo desenvolvido em diferentes unidades da Unesp e, também, nos denominados polos de atendimento presenciais, situados em municípios parceiros bem como em outras dependências disponibilizadas pela Secretaria de Ensino Superior do Estado de São Paulo. A proposta busca contemplar até cinco mil professores em exercício na educação infantil, no ensino fundamental e médio, na abrangência de todo o Estado de São Paulo. Nesta primeira edição, foram ofertadas 1.350 vagas, distribuídas em 21 polos de atendimento presencial nas unidades da Unesp. Na figura 1, estão as cidades que possuem polos de formação, demonstrando a abrangência do programa. 
Figura 1 - Mapa do estado de São Paulo com a localização dos polos que oferecem o curso de pedagogia do programa Unesp/Univesp.

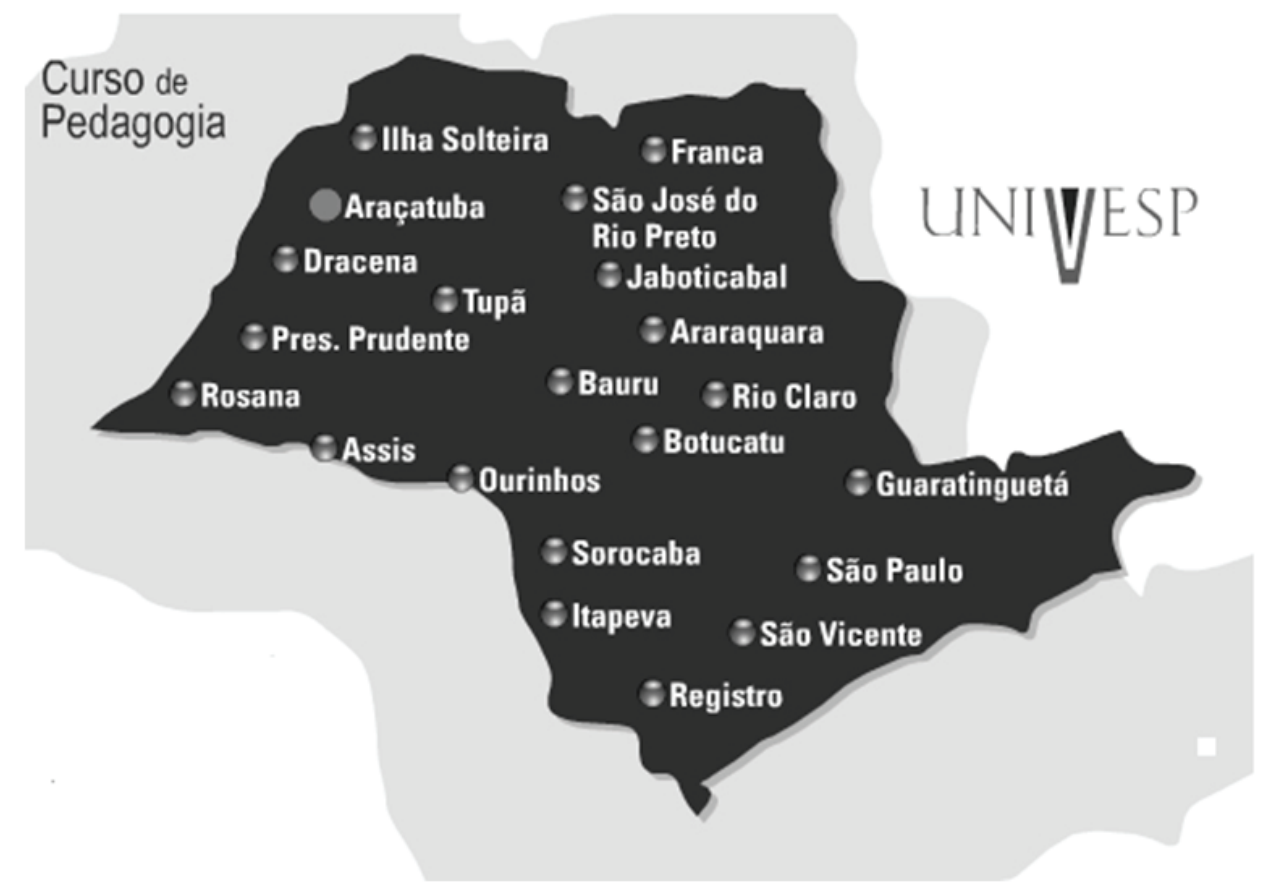

Fonte: Unesp, 2008.

O oferecimento do curso de pedagogia semipresencial é uma parceria entre a Universidade Estadual Paulista e a Universidade Virtual do Estado de São Paulo (Univesp) e se apresenta como uma proposta inovadora no Brasil para ampliar as chances de acesso à educação pública superior, oferecida à população do Estado de São Paulo. A Univesp agrega reconhecidas instituições de ensino superior, que se colocam como importantes parceiras: a Universidade Estadual de São Paulo (USP), a Universidade Estadual de Campinas (Unicamp), a Universidade Estadual Paulista Júlio de Mesquita Filho (Unesp) e o Centro Estadual de Ensino Tecnológico Paula Souza (CEETEPS). Também integram a parceria: a Fundação Padre Anchieta (FPA), a Fundação de Amparo à Pesquisa do Estado de São Paulo (Fapesp), a Fundação do Desenvolvimento Administrativo (Fundap - vinculada à Secretaria de Gestão Pública do Estado) e a Imprensa Oficial. Desde o seu lançamento em 2009, cerca de 15 mil alunos já foram atendidos via sistema Univesp, entre cursos de graduação, especialização e extracurriculares.

A Universidade Virtual do Estado de São Paulo foi criada através do Decreto $\mathrm{n}^{0}$ 53.536, de 09 de outubro de 2008, e o programa Univesp foi lançado em agosto de 2009 com objetivo de ampliar o número de vagas públicas no ensino superior e 
promover a abrangência geográfica da oferta dessas vagas. 0 programa tem como função oferecer o suporte material, financeiro e tecnológico aos cursos oferecidos. Às universidades consorciadas cabe elaborar os projetos acadêmicos, os conteúdos dos cursos e o processo de seleção e a avaliação dos alunos.

\section{As atribuições do tutor no programa UNESP/UNIVESP}

Apresentamos brevemente as atribuições do tutor para evidenciar quão numerosas e importantes são as funções que esse profissional assume e desenvolve nesse programa. Elas estão inseridas, sobretudo, no campo educacional e no processo de acompanhamento da aprendizagem dos alunos, o que indica se tratar de uma tarefa educativa, voltada mais para a formação e menos para administração e suporte técnico.

Conforme o disposto na proposta pedagógica do curso (Unesp, 2008), os tutores possuem um grande número de atribuições e devem atuar na coordenação e orientação do trabalho pedagógico da turma assim como na condução das atividades, sendo responsáveis basicamente por: atuar na busca de diferentes estratégias e formas de mediação do aprendizado; executar a mediação requerida pelos recursos didático-pedagógicos; disponibilizar material de conteúdo do curso no ambiente virtual de aprendizagem; realizar a avaliação dos alunos sob sua responsabilidade; acompanhar o progresso dos alunos durante o curso por meio de análises das provas e demais instrumentos de avaliação; registrar no sistema acadêmico de graduação a frequência e o aproveitamento dos alunos; realizar atividades de apoio à área acadêmica; participar dos seminários de formação programados para o curso; participar de reuniões convocadas pelo orientador e pela coordenação central; elaborar relatórios de atividades ao final de cada disciplina; cumprir outras funções solicitadas pela coordenação do curso e executar todas as tarefas necessárias ao bom andamento do trabalho.

\section{0 tutor do programa Unesp/Univesp: resultados e discussão}

\section{Perfil dos tutores: considerações à luz da LDBEN e do projeto pedagógico}

0 processo de seleção realizado pela Fundação para o Vestibular da Unesp Vunesp recrutou 54 tutores para atuar no programa de formação de professores da Unesp/Univesp. Desses, 41 participaram dessa pesquisa. Apresentamos, nesta parte do trabalho, o perfil desses tutores e realizamos algumas considerações frente ao exposto na LDBEN 9.394/1996 e no projeto pedagógico criado pela Unesp para o oferecimento do curso semipresencial de pedagogia. 
A coleta dos dados foi realizada em janeiro de 2013. Os dados referentes ao perfil dos sujeitos serão apresentados em valores absolutos.

A maior parte dos tutores (30) é do sexo feminino, sendo então 11 o número de sujeitos do sexo masculino. A grande maioria declarou-se como casado (18), seguido de divorciado (12), solteiro (8) e viúvo (1). Quanto à faixa etária, a Tabela 1 apresenta as concentrações.

Tabela 1 - Faixa etária

\begin{tabular}{c|c|c|c|c|c}
\hline Faixa etária & 20 a 30 & 31 a 40 & 41 a 50 & 51 a 60 & Mais de 60 \\
\hline $\begin{array}{c}\text { Quantidade de } \\
\text { tutores }\end{array}$ & 3 & 16 & 16 & 4 & 2 \\
\hline
\end{tabular}

Fonte: Dados da pesquisa

Os tutores estão concentrados, em sua maioria, entre 31 e 50 anos, caracterizando - grupo de profissionais tutores desse programa de formação como sujeitos maduros.

Tabela 2 - Curso de formação dos tutores

\begin{tabular}{c|c}
\hline Biologia & 3 \\
\hline Ciências Sociais & 3 \\
\hline Ed. Física & 1 \\
\hline Engenharia & 1 \\
\hline Filosofia & 2 \\
\hline Geografia & 1 \\
\hline História & 5 \\
\hline Letras & 2 \\
\hline Matemática & 1 \\
\hline Pedagogia & 18 \\
\hline Psicologia & 3 \\
\hline Química & 1 \\
\hline
\end{tabular}

Fonte: Dados da pesquisa

A tabela 2 aponta a variedade de formações dos tutores. Da amostra, menos da metade dos sujeitos (18) possuem formação inicial em pedagogia, curso em que atuam como tutores. A maioria (24) formou-se em instituições públicas de ensino 
superior, sendo 17 provenientes de instituições privadas.

Neste ponto, é importante observar que a proposta pedagógica estabelece como escolaridade mínima para atuação como tutor a licenciatura em curso de pedagogia. Não sendo esta uma exigência do processo seletivo, os objetivos contemplados na proposta não foram atingidos em sua plenitude.

Tabela 3 - Nível de escolaridade

\begin{tabular}{c|l}
\hline Mestrado & 24 \\
\hline Doutorado & 7 \\
\hline Especialização & 9 \\
\hline Graduação & 1 \\
\hline
\end{tabular}

Fonte: Dados da pesquisa

De acordo com a tabela 3, os tutores apresentam, de maneira geral, um bom nível de escolaridade. Mais da metade da amostra (24) possui como grau máximo o mestrado. E 7 tutores possuem doutorado. Acreditamos que isso se deve, em parte, ao edital, que oferecia uma grande pontuação para os que possuíam mestrado e doutorado. Outra razão, e talvez a principal, para o bom nível de escolaridade se deve ao fato de que o vínculo não se dá por meio de uma bolsa. Ao contrário, os tutores da Unesp/Univesp foram contratados com o regime celetista e com valor salarial acima do que geralmente é oferecido para se exercer o cargo de tutor, o que colaborou para o interesse de sujeitos com título de mestre e doutor.

Ainda sobre a escolaridade, percebemos que o programa apresenta maior consonância com art. 66 da LDB que garante: "A preparação para o exercício do magistério superior far-se-á em nível de pós-graduação, prioritariamente em programas de mestrado e doutorado". (Brasil,1996, p. 23)

Tabela 4 - Tempo de atuação como tutor

\begin{tabular}{c|c|c|c}
\hline Até 6 meses & 1 a 3 Anos & 3 a 5 Anos & 5 a 10 Anos \\
\hline 2 & 22 & 11 & 6 \\
\hline
\end{tabular}

Fonte: Dados da pesquisa

Tabela 5 - Tempo de atuação no ensino

\begin{tabular}{c|c|c|c}
\hline 2 a 5 anos & 5 a 10 anos & 10 a 20 anos & Mais de 20 anos \\
\hline 3 & 6 & 16 & 16 \\
\hline
\end{tabular}

Fonte: Dados da pesquisa 
A tabela 4 demonstra que a maioria dos sujeitos não possui muitos anos de experiência como tutor. Grande parte (22) afirmou ter entre 1 e 3 anos de experiência, o que pode significar que essa experiência como tutor iniciou no próprio do curso de formação onde atuam (pedagogia da Unesp/Univesp), que teve início no ano de 2010.

A tabela 5 mostra que a maior parte dos tutores possui um bom tempo de atuação no ensino. As maiores concentrações estão entre 10 e 20 anos (16) e mais de 20 anos (16) de experiência. Isso indica que no aspecto experiência profissional há maior consonância com o disposto na proposta pedagógica e com a LDB, que, em seu art. 67, parágrafo único, garante: “A experiência docente é pré-requisito para o exercício profissional de quaisquer outras funções de magistério, nos termos das normas de cada sistema de ensino". (Brasil,1996, p. 23)

Sobre a questão do emprego de tutor, é relevante observar o que aponta o gráfico abaixo.

Gráfico 1 - Emprego de tutor

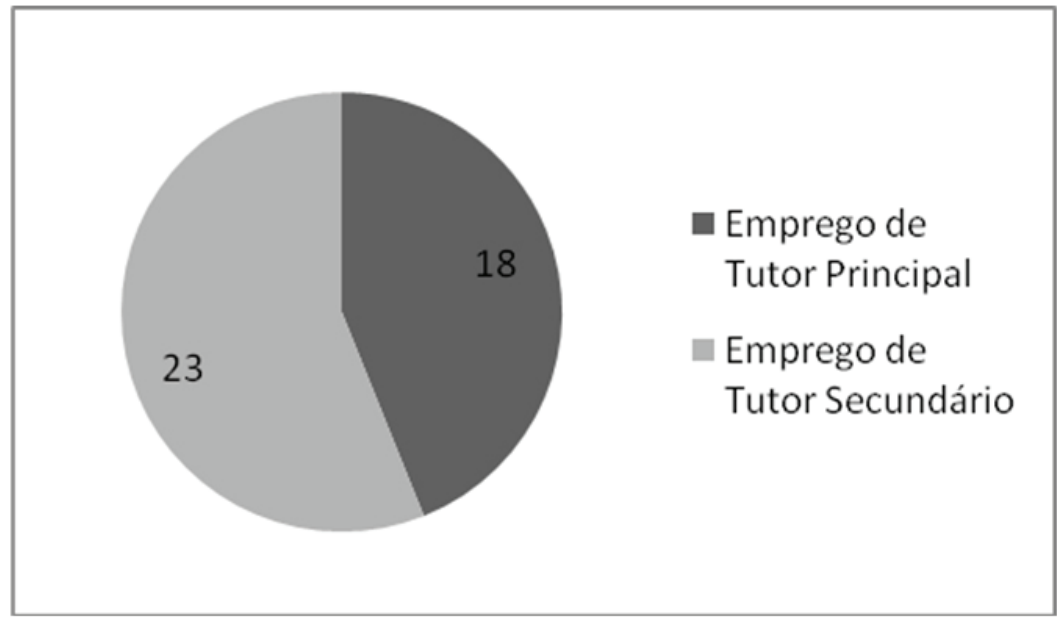

Fonte: Dados da pesquisa

De acordo com o gráfico 1, 23 sujeitos afirmaram que o emprego de tutor não é o principal. Os dados ainda revelam que quase todos os sujeitos (35) declararam possuir outro emprego além do de tutor. Desses, 29 informaram que o outro emprego é presencial e 6 afirmaram que é em EaD.

A constatação de que a maioria dos sujeitos possui outro emprego e não considera o de tutor como o emprego principal sinaliza o que é apontado por Lapa e Pretto (2010) sobre a precarização do trabalho docente na EaD. Segundo os autores, o tutor "é contratado em regime precário para desempenhar o papel de professor" (Lapa; Pretto, 2010, p. 91). Assim, diante de uma carga horária de trabalho exaustiva, de baixa remuneração e de pouco reconhecimento profissional, tem-se uma enorme precarização do trabalho docente. 


\section{Concepções dos tutores sobre a formação em nível superior a distância}

0 interesse em investigar as concepções do tutores do programa Unesp/Univesp deve-se à relevância que tais concepções possuem para o desenvolvimento da própria prática de tutoria. Garnica (2008) esclarece que estudar concepções significa adentrar num meio extremamente dinâmico e inconstante, pois as concepções não são estáveis; ao contrário, estão em constante transformação, ainda que existam algumas zonas de estabilidade. Segundo o autor, concepções são "algos (crenças, percepções, juízos, experiências prévias etc.) a partir dos quais nos julgamos aptos a agir" (Garnica, 2008, p. 499). Assim, nossa intenção foi procurar por essas zonas de estabilidade e perceber o que esses sujeitos pensam do processo formativo a distância e da relevância do trabalho do tutor na educação a distância, modalidade em que atuam por um tempo relativamente curto e que, em boa parte dos casos, se deu na experiência do próprio programa educacional em estudo.

Os tutores responderam a 13 questões sobre aspectos relacionados a formação em nível superior a distância. Tais questões foram disponibilizadas por meio de uma escala do tipo Likert com cinco níveis de resposta. Assim, os sujeitos manifestaram seu grau de concordância sobre as assertivas apresentadas, escolhendo entre as opções: (1) discordo totalmente; (2) discordo; (3) indiferente; (4) concordo, e (5) concordo totalmente.

Os dados obtidos foram submetidos à análise de frequência de alternativa de respostas, utilizando-se para esta finalidade o software Statistical Package for Social Sciences (SPSS) versão 15.0. A seguir, apresentamos os dados e analisamos os resultados de cada questão referente às concepções que os sujeitos apresentam sobre aspectos relacionados a formação em nível superior a distância.

Sobre a procura por cursos a distância e sobre a facilidade em sua realização, os tutores acreditam fortemente que fazer um curso na modalidade a distância não é mais fácil do que fazer um curso presencialmente $(90 \%)$ e que a procura pela EaD não é por conta da facilidade em se diplomar (96\%), crença que muitas pessoas ainda possuem, mas principalmente pela não exigência da presença diária em uma instituição.

A grande maioria dos tutores $(82,9 \%)$ afirmou que ser professor da educação a distância é bem mais complexo do que na modalidade presencial. De fato, como apontado por Mill (2010), na educação a distância, o desenvolvimento do trabalho pedagógico é muito mais complexo do que na educação presencial, principalmente porque muitos sujeitos estão envolvidos na tarefa de ensinar, e a organização e a dinâmica são diferentes daquela a que fomos acostumados durante nossa trajetória escolar.

A literatura, de maneira geral, aponta a complexidade da realização da avaliação da aprendizagem enquanto processo. Gaytan e McEwen (2007) ressaltam que o 
terreno relativamente novo da EaD traz desafios ainda maiores aos tutores devido à necessidade de acompanhar e avaliar as tarefas dos alunos em ambiente virtual não como uma prestação de contas, mas como uma forma de contribuir para a aprendizagem significativa. Interessante observar que, dos tutores do programa Unesp/Univesp participantes dessa investigação, apenas $24,4 \%$ afirmaram que na EaD é mais difícil realizar a avaliação devido ao grande número de tarefas e 17,1\% afirmaram que na EaD é mais difícil realizar a avaliação devido ao grande número de alunos. Acreditamos que esse baixo descontentamento com a quantidade de tarefas e alunos pode ser um indicativo da forma como foi pensado e organizado o programa como um todo: gestão do ambiente, da quantidade e qualidade das atividades, do número de alunos por tutor, dentre outros. Inclusive, sobre este último aspecto, o programa se apresenta em consonância com o exposto por Palloff e Pratt (2004), quando sugere que professores experientes no ensino on-line podem ter até 25 alunos. No programa Unesp/Univesp, há 50 alunos e dois tutores por turma, sendo 25 o número de alunos para cada tutor.

Ao serem indagados se o aluno tem as mesmas condições de aprender tanto no ensino presencial quanto na educação a distância, a maior parte dos sujeitos $(70,7 \%)$ concordou com a afirmação, e mais da metade da amostra $(56,1 \%)$ considera que a falta de contato físico não prejudica a aprendizagem dos alunos. Contudo, é preciso levar em consideração que um número considerável de sujeitos se manifestou contrário à última sentença, indicando a necessidade de encontros presenciais. Para Giolo (2008), a prática da experimentação, da convivência, dos debates e conversas não se realiza completamente por relações instrumentalmente mediadas, pois os seres humanos necessitam da presença do outro. Em função disso, o autor argumenta a favor da oferta de cursos a distância com encontros de formação presenciais regulares.

Sobre a relevância do trabalho do tutor, é interessante observar o que apontam os resultados. Da amostra, menos da metade dos sujeitos $(43,9 \%)$ considera que 0 tutor é o maior responsável pelo sucesso do curso. Entretanto, 80,5\% afirmaram que o tutor é o grande responsável pela qualidade da interação entre os alunos. Por um lado, os sujeitos se responsabilizam por ações e intervenções desenvolvidas que visam à qualidade da interação que ocorre entre os alunos. Por outro, julgam, em escala considerável, não serem os maiores responsáveis pelo sucesso dessa empreitada de formação, deixando claro que outros aspectos devem ser levados em consideração quando se trata de apontar os maiores responsáveis pelo sucesso do curso. Contudo, é importante enfatizar o que aponta Belloni (2009), quando afirma que o tutor possui, inegavelmente, uma função pedagógica e é ele que tem de dar conta da difícil tarefa de levar o aluno a aprender no ambiente virtual. Posto isso, o tutor é um dos pilares (e talvez o mais importante) sobre o qual se consolida a EaD. (Padula, 2002)

A resposta dos tutores à assertiva: "Acredito que os materiais instrucionais são suficientes para promover uma excelente aprendizagem" pode ser uma justificativa 
para o fato de um bom número deles considerar que não são os maiores responsáveis pelo sucesso do curso, pois 39\% concordaram com a sentença e $14,6 \%$ foram indiferentes. 0 material didático é parte importante da grande maioria dos projetos e programas em EaD. Nele estão contidos os conceitos, as ideias e as reflexões fundamentais para as construções de significados que se desejam produzir no desenvolvimento do currículo. É o material didático “que possibilita que as diretrizes e os princípios definidos no projeto político pedagógico do curso sejam garantidos no desenvolvimento da prática pedagógica" (Neder, 2009, p.81). Acreditar, no entanto, que os materiais instrucionais conseguem, sozinhos, dar conta de uma excelente aprendizagem significa reduzir ou mesmo retirar a grande importância do trabalho de mediação pedagógica que se espera do tutor e se deseja ver realizado por ele no processo de colaboração da construção de aprendizagens pelos alunos.

Do total de sujeitos, $80,5 \%$ discordaram que a EaD só é procurada por aquelas pessoas que não podem cursar o ensino presencial, demonstrando que os tutores acreditam, de maneira geral, que fazer um curso a distância é uma escolha e não falta de opção.

A maioria dos tutores participantes (68,3\%) afirmou não se sentir desvalorizado ao relatar para alguém que trabalha com educação a distância. Assim, percebemos que a maioria dos tutores que atua nesse programa considera que trabalhar com formação de professores tanto no ensino presencial quanto na modalidade a distância possui, ambos, a relevância e a responsabilidade de cuidar de sujeitos em processo de formação.

Por último, é relevante observar que a maior parte dos sujeitos $(51,2 \%)$ não acredita que o profissional formado a distância é tão bem aceito pelo mercado de trabalho quanto o profissional formado pelo ensino presencial, evidenciando que há a crença de que os formados nesta modalidade enfrentarão preconceitos no mercado de trabalho. Percebemos que esta é uma questão polêmica e que os sujeitos manifestaram-se bastante divididos, caracterizando esta questão como relevante a ser investigada com maior profundidade.

\section{Considerações finais}

É consenso na literatura, e sabido por aqueles que se dedicam a investigar a prática do tutor e o processo de formação a distância, que o profissional tutor desempenha e ocupa papel fundamental no processo de mediação em cursos superiores na modalidade a distância. Os Referenciais de Qualidade para Educação Superior a Distância (Brasil, 2007) inserem o papel do tutor no processo de mediação e afirmam que sua principal tarefa é participar ativamente do desenvolvimento do processo de ensino-aprendizagem dos professores em formação. 0 tutor, desta forma, se constitui em um dos pilares sobre o qual se consolida a educação a 
distância. (Padula, 2002)

No programa de formação de professores em exercício da Unesp/Univesp não é diferente o lugar ocupado pelo profissional tutor. Ele é responsável por realizar a mediação pedagógica tanto em ambiente virtual quanto nos encontros presenciais semanais. Também é dele a responsabilidade de realizar a avaliação dos alunos e acompanhar seu desenvolvimento durante o curso por meio de análises das provas e demais instrumentos de avaliação. Tratam-se, pois, de tarefas educativas, voltadas à prática pedagógica que exige desses profissionais conhecimentos específicos sobre o processo de ensino-aprendizagem, sobre avaliação e sobre formação de professores em ambiente virtual de aprendizagem.

Acreditamos que o fato de haver dois tutores por sala indica que o programa compreende características e necessidades específicas da formação a distância, que exige maior disponibilidade por parte dos formadores para o acompanhamento do processo de aprendizagem dos alunos. Dois tutores atuando em uma mesma turma significa, além de conseguir acompanhar melhor o caminho trilhado pelos alunos em formação, poder discutir, entre pares, sobre questões pertinentes ao processo de aprendizagem, sobre a condução e planejamento das aulas e sobre dúvidas e entraves que surgem ao longo do desenvolvimento do curso.

As concepções dos tutores do programa Unesp/Univesp sobre aspectos da formação a distância demonstram que, de maneira geral, esses profissionais acreditam nas possibilidades da educação a distância para a formação de qualidade de professores e consideram o trabalho de tutoria fundamental para garantir a qualidade da interação entre os alunos. Os materiais instrucionais ocupam um lugar de destaque no processo de aprendizagem para um número considerável de sujeitos. Também fica evidente em suas concepções que o preconceito com a EaD ainda é forte no mercado de trabalho e na sociedade.

0 perfil e as concepções dos tutores do programa Unesp/Univesp reforçam o que é apontado substancialmente na literatura: a necessidade da formação continuada desses profissionais, principalmente quando se trata de compreender a dinâmica que se estabelece na educação a distância e a construção colaborativa do conhecimento. A relevância do trabalho realizado pelos tutores exige acompanhamento contínuo desses profissionais como condição necessária, ainda que insuficiente, para promover práticas emancipatórias, comprometidas com o sucesso da aprendizagem dos alunos.

\section{Referências}

ALONSO, Myrtes; ALEGRETTI, Sonia Maria. Introduzindo a pesquisa na formação de professor a distância. In: ALMEIDA, Maria Elisabette Bianconcini. et al (orgs). Educação a distância via internet. São Paulo: Avercamp, 2003. 
BELLONI, Maria Luiza. Educação a Distância. Campinas: Autores Associados, 2003. BELLONI, Maria Luiza. Educação a distância. Campinas: Autores Associados, 2009. BRASIL. MEC. Secretaria de Educação a Distância. Referenciais de qualidade para educação superior a distância, 2007. Disponível em: <http://portal.mec.gov.br/seed>. Acesso em: 09 set. 2011.

BRASIL. Lei no 9.394, de 20 de dezembro de 1996. Estabelece as diretrizes e bases da educação nacional. Diário Oficial da República Federativa do Brasil, Brasília, DF, 23 dez. 1996. Disponível em: <http://portal.mec.gov.br/arquivos/pdf/diretrizes.pdf>. Acesso em: 04 jul. 2011.

BRASIL. MEC. Secretaria de Educação a Distância. Decreto no 5.800, de 8 de junho de 2006. Dispõe sobre o Sistema Universidade Aberta do Brasil - UAB. Disponível em: <http://www.planalto.gov.br/ccivil_03/_ato2004-2006/2006/decreto/d5800.htm>. Acesso em: 12 fev. 2012.

DIAS SOBRINHO, José. Democratização, qualidade e crise da educação Superior: faces da exclusão e limites da inclusão. Educação e Sociedade. Campinas, v. 31, n. 113, p. 1223-1245, out.-dez. 2010.

GARCÍA ARETIO, Lorenzo. La educación a distância. Uma visión global. Boletín Llustre Colegio de Doctores y licenciados de España. 2003. Disponível em: <http:// www. uned. es/ catedraunesco-ead/articulos/2003/la\%20educacion\%20a\%20distancia\%20una \%20vision\% 20global.pdf>. Acesso em: 17 dez. 2011.

GARNICA, A. V. M. Um ensaio sobre as concepções de professores de matemática: possibilidades metodológicas e um exercício de pesquisa. Educação e Pesquisa: São Paulo, v.34, n.3. p.495-510, set.-dez. 2008.

GAYTAN, Jorge; MCEWEN, Beryl. Effective online instructional and assessment strategies. The American Journal of Distance Education. p. 117-132.2007. Disponivel em: <http://onlinelearningassessment.pbworks.com/f/gaytan.pdf>. Acesso em: 22 jan. 2012.

GIOLO, Jaime. A educação a distância e a formação de professores. Educação e Sociedade. Campinas, vol. 29, n. 105, p. 1211-1234, set.-dez. 2008. Disponível em: <http://www.cedes.unicamp.br>. Acesso em: 07 dez. 2011.

KENSKI, Vani Moreira. Novas tecnologias: o redimensionamento do espaço e do tempo e os impactos no trabalho docente. Revista Brasileira de Educação, nº 08, Mai/ Jun/Jul/Ago, 1998. Disponível em: <http://educa.fcc.org.br/pdf/rbedu/n08/n08 a06. pdf>. Acesso em: 25 maio 2010.

LAPA, Andrea; PRETTO, Nelson de Luca. Educação a distância e precarização do trabalho docente. Em Aberto, Brasília, v. 23, n. 84, p. 79-97, nov. 2010.

MAGGIO, Mariana. 0 tutor na educação a distância. In: LITWIN, Edith. (org.). Educação a Distância. Porto Alegre: Artmed, 2001, p. 93-110.

MILL, Daniel. Sobre o conceito de polidocência ou sobre a natureza de trabalho pedagógico na Educação a Distância. In: MILL, Daniel; OLIVEIRA, M. R. G.; RIBEIRO, L. R. C. (Org.) Polidocência na educação a distância: múltiplos enfoques. São Carlos: EDUFSCar, 2010. 
MOORE, Michael; KEARSLEY, Greg. Educação a distância: uma visão integrada. São Paulo: Cengage Learning, 2008.

NEDER, Maria Lúcia Cavalli. 0 texto como elemento de mediação entre os sujeitos da ação educativa. In: POSSARI, Lucia Helena Vendrúsculo; NEDER, Maria Lúcia Cavalli. Material Didático para a EaD: Processo de Produção. Cuiabá: EdUFMT, 2009. PADULA, Jorge. Eduardo. Contigo em La distancia: el rol del tutor em La educación no presencial, 2002. Disponível em: <http://www.uned.es/catedraunescoead/ publicued/pbc08/rol_bened.htm>. Acesso em: 27 nov. 2012.

PALLOFF, Rena; PRATT, Keith. Oaluno virtual: um guia para trabalhar com estudantes on-line. Porto Alegre: Artmed, 2004.

PRETI, Oreste. 0 estado da arte sobre "tutoria": modelos e teorias em construção. In: PRETI, 0. 0 sistema de Orientação Acadêmica no curso de Pedagogia a distância da Universidade Federal de Mato Grosso. Programa CAERENAD, 2005.

SCHLEMMER, Eliane. Formação de professores na modalidade online: experiências e reflexões sobre a criação de espaços de convivências digitais virtuais. Em Aberto, v. 23, n. 84, p. 99-122, nov. 2010.

UNESP. Projeto Pedagógico do curso de Pedagogia semipresencial, 2008. $35 \mathrm{pg}$. Disponível em: <http://www.edutec.unesp.br/images/portal/ementas/completo1. pdf>. Acesso em: 21 nov. 2012.

Recebido em julho de 2013

Aprovado em setembro de 2013

Marta Fernandes Garcia é mestra em Educação pela Universidade Estadual de Campinas. E-mail: marta_fgarciađyahoo.com.br.

Dirceu da Silva é doutor em Educação pela Universidade de São Paulo. Professor da Faculdade de Educação da Universidade Estadual de Campinas. E-mail: dirceula unicamp.br. 